\title{
Cell division in cocci: localization and properties of the Streptococcus pneumoniae FtsA protein
}

\author{
Beatriz Lara, ${ }^{1 \dagger}$ Ana Isabel Rico, ${ }^{2 \dagger}$ Sabrina Petruzzelli, ${ }^{3}$ \\ Antonella Santona, ${ }^{3}$ Jacques Dumas, ${ }^{1}$ Jacques Biton, ${ }^{1}$ \\ Miguel Vicente, ${ }^{2}$ Jesús Mingorance ${ }^{2}$ and \\ Orietta Massidda ${ }^{3 *}$ \\ ${ }^{1}$ Aventis Pharma, 102 Route de Noisy, F-93235 \\ Romainville cedex, France. \\ ${ }^{2}$ Centro Nacional de Biotecnología, Consejo Superior de \\ Investigaciones Científicas, Campus de Cantoblanco, \\ 28049 Madrid, Spain. \\ ${ }^{3}$ Dipartimento di Scienze e Tecnologie Biomediche, Sez. \\ Microbiologia Medica, Università di Cagliari, Via Porcell, \\ 4. 09100 Cagliari, Italy.
}

\section{Summary}

We studied the cytological and biochemical properties of the FtsA protein of Streptococcus pneumoniae. FtsA is a widespread bacterial cell division protein that belongs to the actin superfamily. In Escherichia coli and Bacillus subtilis, FtsA localizes to the septal ring after FtsZ, but its exact role in septation is not known. In S. pneumoniae, we found that, during exponential growth, the protein localizes to the nascent septa, at the equatorial zones of the dividing cells, where an average of $2200 \mathrm{FtsA}$ molecules per cell are present. Likewise, FtsZ was found to localize with the same pattern and to be present at an average of $\mathbf{3 0 0 0}$ molecules per cell. Consistent with the colocalization, FtsA was found to interact with FtsZ and with itself. Purified FtsA is able to bind several nucleotides, the affinity being highest for adenosine triphosphate (ATP), and lower for other triphosphates and diphosphates. The protein polymerizes in vitro, in a nucleotide-dependent manner, forming long corkscrew-like helixes, composed of $2+2$ paired protofilaments. No nucleotide hydrolytic activity was detected. Consistent with the absence of an ATPase activity, the polymers are highly stable and not dynamic. These results suggest that the FtsA protein could also polymerize in vivo and the polymers participate in septation.

Accepted 12 October, 2004. *For correspondence. E-mail omassid@vaxca1.unica.it; Tel. (+39) 070 6758485; Fax (+39) 070 6758482. 'Beatriz Lara and Ana Isabel Rico contributed equally to this work.

\section{Introduction}

FtsA is among the proteins that form the septation machinery in most bacteria. It is an adenosine triphosphate (ATP)-binding protein structurally related to the actin-hexokinase-Hsp70 family (Bork et al., 1992; Hurley, 1996; van den Ent and Löwe, 2000). The fts $A$ gene is clustered with other cell division and wall synthesis genes in the dcw cluster (Ayala et al., 1994), that is highly conserved in bacilli, and to a lesser extent in cocci (Pucci et al., 1997; Massidda et al., 1998; Tamames et al., 2001). In both cocci and bacilli, the fts $A$ gene is usually found adjacent and upstream of fts $Z$ (Nikolaichik and Donachie, 2000). Although considerable evidence has been recently gathered on the properties of the cell division proteins in rods (Margolin, 2000; Errington et al., 2003), this is not so for cocci. FtsA is essential in Escherichia coli (Lutkenhaus and Donachie, 1979) and Caulobacter crecentus (Sackett et al., 1998) while in Bacillus subtilis, deletion of ftsA leads to a severe impairment of growth and a reduction of viability and sporulation (Beall and Lutkenhaus, 1992). In E. coli and in vegetatively growing $B$. subtilis cells, FtsA is placed into a central ring structure at the initial steps of the division process, depending on the previous localization of FtsZ (Addinall and Lutkenhaus, 1996; Ma et al., 1996; Feucht et al., 2001) and a proper FtsZ/FtsA ratio has been suggested to be required for cell division to occur (Dai and Lutkenhaus, 1992; Dewar et al., 1992). FtsA and FtsZ may interact in vivo (Descoteaux and Drapeau, 1987; Vicente and Errington, 1996; Ma et al., 1997) and both genetic and biochemical studies have shown in vitro interactions between these proteins in different bacteria (Descoteaux and Drapeau, 1987; Ma et al., 1997; Wang et al., 1997; Din et al., 1998; Ma and Margolin, 1999; Yan et al., 2000). The extreme C-terminus of FtsZ has been reported to be involved in its interaction with FtsA (Din et al., 1998; Ma and Margolin, 1999; Yan et al., 2000). In addition, E. coli FtsA is also able to interact with itself and the correct establishment of these interactions is required for septation (Yim et al., 2000). The conserved C-terminal end of the protein is involved in this self interaction and also in the proper localization of FtsA into septal rings (Yim et al., 2000).

The nucleotide-binding site of FtsA, located in a cleft formed by subdomains $1 \mathrm{~A}, 2 \mathrm{~A}$ and $2 \mathrm{~B}$, is very similar to that of the other members of the actin family, which are 
able to assemble into polymers in an ATP-dependent manner (Carlier, 1994; van den Ent and Löwe, 2000; van den Ent et al., 2001; van den Ent et al., 2002). Consistently, the FtsA proteins from E. coli, Thermotoga maritima and $B$. subtilis are able to bind ATP in vitro (Sánchez et al., 1994; van den Ent and Löwe, 2000; Yim et al., 2000; Feucht et al., 2001), although no evidence for FtsA polymerization has been so far reported. Besides the similarities with the actin superfamily, the crystal structure shows that the fold and the topology of subdomain $1 \mathrm{C}$ are unique to FtsA, suggesting that this subdomain plays an FtsAspecific role (van den Ent and Löwe, 2000).

More recently, Carettoni et al. (2003) identified a region of subdomain $1 \mathrm{C}$ (residues 126-133) also involved in the homodimerization of $E$. coli FtsA and demonstrated that this region is essential for FtsA activity. It was also speculated that FtsA binding to ATP could regulate this FtsA homodimerization by settling subdomain $1 \mathrm{C}$ into a favourable orientation (Carettoni et al., 2003).

Despite all this information, the precise role of FtsA in cell division is unknown. The only biochemical function described for FtsA is binding of ATP (Sánchez et al., 1994; van den Ent and Löwe, 2000; Yim et al., 2000; Feucht et al., 2001). ATP hydrolysis has been reported for $B$. subtilis FtsA (Feucht et al., 2001), but it has not been detected with the FtsA proteins from E. coli and T. maritima (J. Mingorance and M. Vicente, unpubl. data). The physiological significance of the FtsA ATP-binding and/or hydrolysis has never been described.

In this work, we report the characterization of the FtsA protein from the Gram-positive coccus Streptococcus pneumoniae, a major human pathogen. We found that, in addition to several features in common with homologous FtsA proteins already studied, S. pneumoniae FtsA (FtsA) is able to polymerize in vitro in an ATP-dependent manner, indicating for the first time a possible role of ATP binding in the protein.

\section{Results}

The ftsA gene is essential in S. pneumoniae, and its product localizes at the mid-cell in a ring-like structure

To determine the essentiality of the ftsA gene in $S$. pneumoniae, we attempted to disrupt its chromosomal copy by insertion/deletion mutagenesis. Inactivations of the fts $Z$ and $y / m E$ genes were used as internal controls for the disruption of an essential (Baltz et al., 1998) and a nonessential (Fadda et al., 2003) gene respectively. Constructs for inactivations were obtained by a two-step polymerase chain reaction (PCR) method as previously described (Fadda et al., 2003) and were used to transform S. pneumoniae competent Rx1 cells. An internal fragment of the pneumolysin (ply) gene cloned in the suicide vector
pR326 (Claverys et al., 1995) was used as a positive control for transformation. The experiment was performed three times, and an average of 400 and 100 transformants per experiment were obtained with the positive controls for transformation ply::cat and ylmE::cat respectively. In contrast, no transformants were obtained for ftsA::cat or ftsZ::cat, after up to $48 \mathrm{~h}$ of incubation, indicating that the inactivation of either of the fts genes would be lethal for the streptococcal cells, and thus suggesting that $f t s$ is essential in S. pneumoniae.

The subcellular localization of FtsA and FtsZ in S. pneumoniae Rx1 was examined by both immunoelectron and immunofluorescence microscopy. Exponentially growing cells were fixed and processed for immunolabelling with specific antisera raised against the recombinant FtsA and FtsZ streptococcal proteins, as described in the Experimental procedures. For electron microscopy, thin sections were incubated with the primary antibodies and then with colloidal gold-labelled secondary antibodies. The localization of the proteins was studied by analysing the distribution of the gold beads in the cells. A total of 204 beads in 24 cells for FtsZ, and 211 beads in 34 cells for FtsA were counted. A similar localization for both proteins was observed in sections of the cells from the same culture, results for the localization of FtsA are shown in Fig. 1A. Around $10 \%$ of the beads were found outside of the cells, of the remaining, $60 \%$ were at the leading edge of the invagination, $30 \%$ at the equatorial zones of the future daughter cells and $10 \%$ at the poles. This is in agreement with previous models for streptococcal cell wall growth and cell division (Cole and Hahn, 1962; Briles and Tomasz, 1970; Higgins and Shockman, 1970). Notably, both cytoplasmic proteins, FtsA and FtsZ, were primarily localized near the membrane. In longitudinal sections, all cells containing a constriction presented a cluster of label at the leading edges of the invagination. The symmetrical labelling pattern in thin sections indicates that both FtsA and FtsZ proteins must form a ring. Immunofluorescence experiments confirmed that FtsA localizes in a ring-like structure at the currently active and at the future division sites of streptococcal cells, as shown in Fig. 1B. The fluorescence pattern of the ring changes with the progression of division. A very similar pattern of localization was observed for FtsZ (data not shown).

\section{S. pneumoniae FtsA protein interacts with itself and with FtsZ}

Interactions of FtsA with FtsZ and with itself have been described in other organisms (Descoteaux and Drapeau, 1987; Ma et al., 1997; Wang et al., 1997; Din et al., 1998; Ma and Margolin, 1999; Yan et al., 2000; Yim et al., 2000). Moreover, as the ability of $E$. coli FtsA for self interaction is the only described feature that is related to an activity 
A

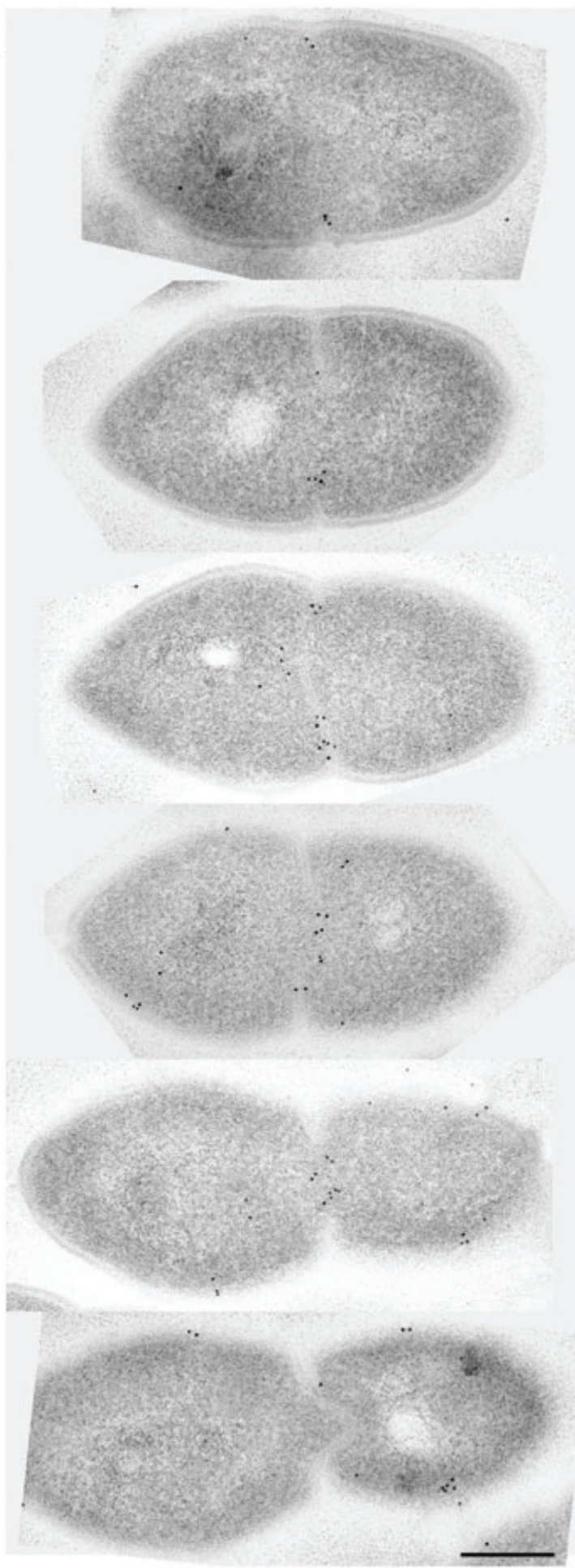

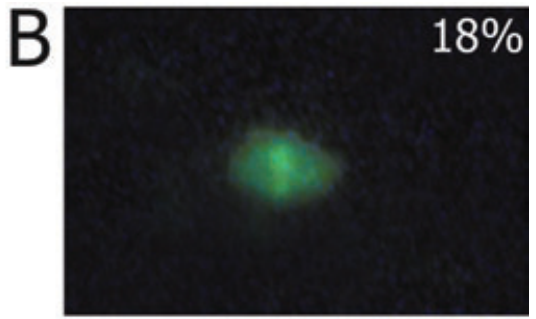
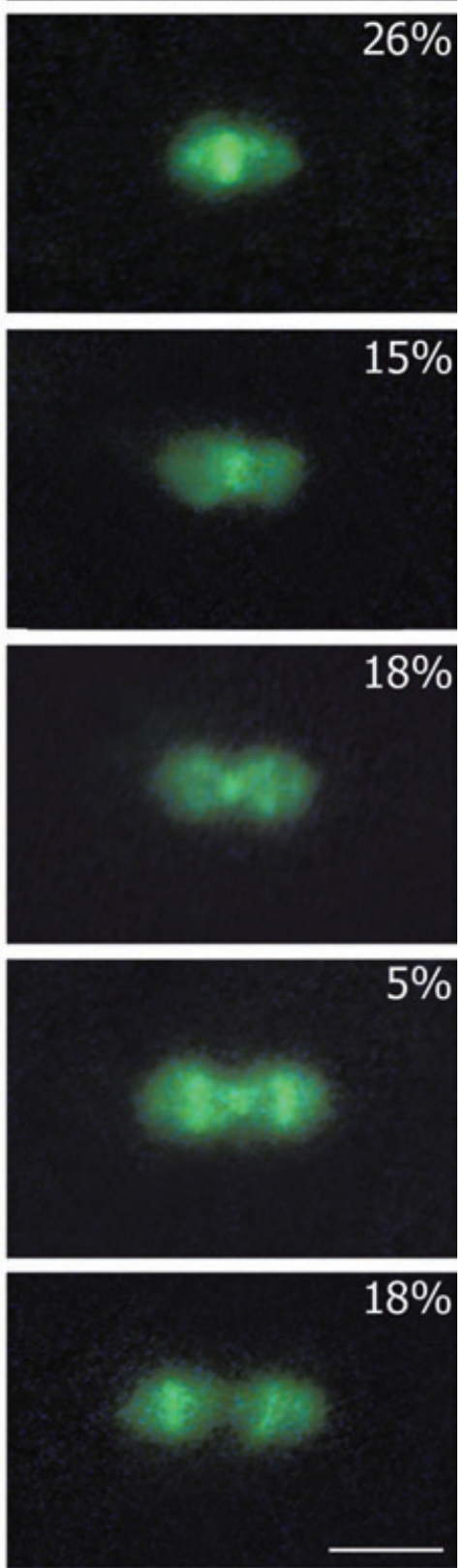

Fig. 1. Localization of the FtsA protein in S. pneumoniae Rx1 cells.

A. Exponentially growing cells were fixed and freeze-substituted. Thin sections were immunolabelled with specific antibodies, and a gold-labelled secondary antibody and analysed by electron microscopy. Dark grains show the localization of FtsA. Selected cells representing different degrees of septation are shown. The scale bar represents $0.25 \mu \mathrm{m}$.

B. Fluorescence micrographs showing the ring-like localization of FtsA in streptococcal cells at different stages of division. The percentage of cells in each stage is given in the upper right corner of the respective image. The first and the fourth stages show the same pattern of localization in a single cell or a diplococcus respectively. The pattern of localization observed in the second stage is equivalent to the pattern of the fifth and sixth stages. The scale bar represents $0.45 \mu \mathrm{m}$. 
of FtsA in cell division (Yim et al., 2000; Carettoni et al., 2003), we analysed the interacting properties of FtsA by the yeast two-hybrid assay. The fts $A$ and $f t s Z$ genes were each fused to the GAL4-binding and to the GAL4-activation domain sequences and the resulting recombinant plasmids were transformed into the yeast reporter strain AH109.

Single transformants producing the FtsZ protein fused to the GAL4-binding domain activated the expression of the reporter gene, as previously observed for the $E$. coli FtsZ protein (Huang et al., 1996), therefore the interaction of FtsZ with itself could not be tested with this procedure. None of the other single transformants, expressing FtsA and FtsZ fusions, was able, by itself, to activate the expression of the reporter gene. The combinations of the two FtsA fusions, and the combination of FtsA fused to the GAL4 DNA-binding domain with FtsZ fused to the GAL4 activation domain, resulted in transformants able to induce the expression of the reporter gene, indicating that FtsA is able to interact with itself and with FtsZ as determined by the light-blue and the blue colour observed on plates respectively.

\section{Determination of FtsA and FtsZ copy number} in S. pneumoniae

A stoichiometric FtsZ/FtsA balance is believed to be crucial for cell division (Dai and Lutkenhaus, 1992; Dewar et al., 1992). Recent studies in both B. subtilis and E. coli have indicated a $1: 5$ ratio for FtsA with respect to FtsZ (Feucht et al., 2001; Rueda et al., 2003), although previous works indicated in E. coli a ratio of 1:100 (Wang and Gayda, 1992). Therefore, following the verification of FtsZ and FtsA interactions, a further step in FtsA characterization was to determine its amount in S. pneumoniae cells and to compare its abundance with that of FtsZ.

To quantify the streptococcal FtsA and FtsZ proteins, extracts of $S$. pneumoniae Rx1 cells grown to exponential phase were analysed by Western blotting with specific antibodies raised against the purified streptococcal proteins as described in Experimental procedures. The average numbers of FtsA and FtsZ molecules per streptococcal cell were estimated to be 2200 and 3000 respectively, corresponding to an FtsA/FtsZ ratio of $1: 1.5$.

\section{Purified FtsA preferentially binds nucleotide triphosphates}

To investigate the biochemical properties of FtsA, we overproduced and purified this protein using $\mathrm{Zn}^{2+}$-affinity chromatography followed by gel filtration (see Experimental procedures). Purity of FtsA was estimated to be higher than $98 \%$ by SDS-PAGE gel stained with Coomassie blue (Fig. 2A). Analysis of the gel filtration fractions showed that the protein elutes with an apparent molecular weight of $60-70 \mathrm{kDa}$ (Fig. 2B), which is higher than the $49.3 \mathrm{kDa}$ theoretical value calculated from the sequence, and indicates that the protein might be a monomer with a slightly anomalous chromatographic mobility or an equilibrium mixture of monomers and dimers. To distinguish between these two possibilities the protein was analysed by sedimentation velocity in an analytical ultracentrifuge. There was a major peak with a sedimentation coefficient of 3.2, which is compatible with a monomer (there were in addition a shoulder and a minor peak with coefficients of 5.7 and 15.7, which might correspond to a dimer and a large oligomer of around 10 subunits; Fig. 2C). It was concluded therefore that the streptococcal FtsA protein was purified as a monomer, and that the higher molecular weight of the protein observed in gel filtration chromatography might result from the lower mobility of an elongated monomer. Indeed, the opposite orientations of domains $2 \mathrm{~B}$ and $1 \mathrm{C}$ in the FtsA protein from T. maritima make the monomer to be elongated, rather than spherical (van den Ent and Löwe, 2000).

Both sequence similarity and $3 D$-structure indicate that FtsA belongs to the sugar kinase/hsp70/actin superfamily (Bork et al., 1992; Hurley, 1996; van den Ent and Löwe, 2000). The biochemical activity of FtsA is not known, but binding of ATP by FtsA molecules in several organisms has been reported (Sánchez et al., 1994; van den Ent and Löwe, 2000; Yim et al., 2000; Feucht et al., 2001). Therefore, we studied the activity of the streptococcal FtsA protein by measuring the binding of ATP in a nitrocellulose filter-binding assay. The purified protein bound $1 \mathrm{~mol}$ of ATP per mole of protein in a $\mathrm{Mg}^{2+}$-dependent manner, and had a rather low affinity for ATP (IC50 = $8 \mu \mathrm{M}$ measured in competitive binding assays, Table 1), which is similar to the affinity of T. maritima FtsA for ATP (J. Mingorance and M. Vicente, unpubl. results).

Table 1. In vitro binding affinities of $\mathrm{Fts}^{\mathrm{a}}$ and polymerization levels with several nucleotides ${ }^{\mathrm{b}}$.

\begin{tabular}{lcc}
\hline Nucleotides & IC50 in $\mu \mathrm{M}$ & Relative polymerization levels \\
\hline ATP & 8 & 100 \\
GTP & 79 & 65 \\
ATP- $\gamma$-S & 60 & 93 \\
ADP & 955 & 96 \\
AMP & $>5000$ & 16 \\
AMP-PCP & $>>5000$ & 38 \\
AMP-PNP & 1300 & 100 \\
\hline
\end{tabular}

a. Binding was monitored by competition binding and nitrocellulose filtering in the presence of $\left[\gamma^{-33} \mathrm{P}\right]-$ ATP and different nucleotides. Binding affinities were determined using the GraFit 5 program (Erithacus Software).

b. Relative polymerization levels are expressed in each case as the percentage of their value with respect to the value obtained in the presence of ATP. Values were calculated from densitometric analysis of the resuspended pellets after migration in SDS-PAGE gels.

All values are representative of two independent experiments. 
A

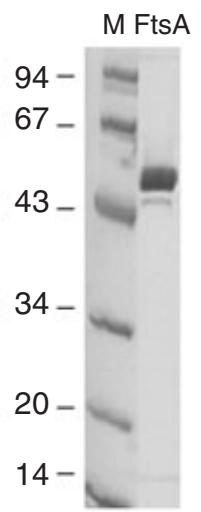

B

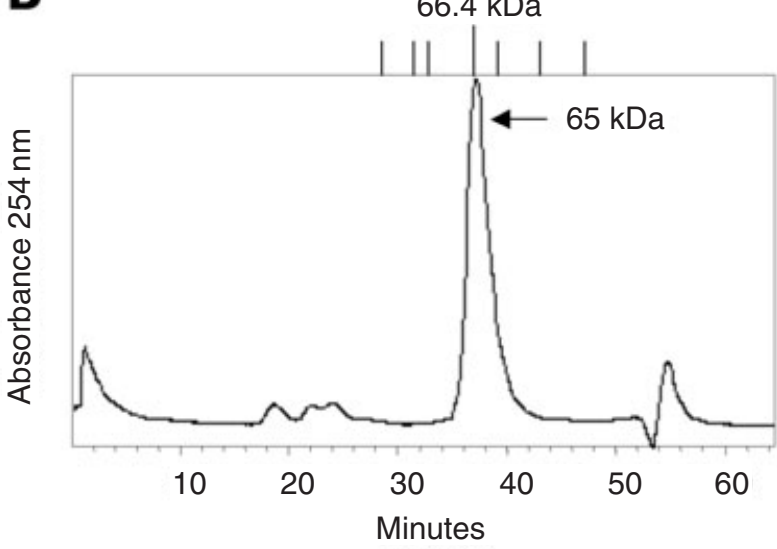

Fig. 2. Purified FtsA behaves predominantly as a monomer. Overproduced FtsA was purified by two consecutive chromatographies and the molecular weight of the protein was determined by different methods.

A. Coomassie blue stained 4-12\% Nu-PAGE ${ }^{\circledR}$ Novex ${ }^{\circledR}$ gel of purified FtsA $(5 \mu \mathrm{g})$. Molecular weight standards are shown in the left lane. The faint lower band is a degradation product of FtsA.

B. Gel filtration chromatography of the purified protein in a Superdex 200 column. The protein elutes as a single peak with a molecular mass of $65 \mathrm{kDa}$. The elution times of the molecular weight standards are indicated by lines on top of the plot. The molecular weights of the standards were from left to right: apoferritin (443 kDa), $\beta$-amylase (200 kDa), alcohol dehydrogenase (147 kDa), albumin (66.4 kDa), ovalbumin (46.8 kDa), carbonic anhydrase $(29 \mathrm{kDa})$, and cytochrome $c(12.3 \mathrm{kDa})$. C. Size-distribution analysis of a sedimentation velocity experiment with purified FtsA. The major peak of protein has a sedimentation coefficient of 3.2, which is compatible with a monomer. The shoulder and the minor peak have sedimentation coefficients of 5.7 and 15.7, which are compatible with a small amount of dimer and a oligomer of approximately 10 subunits.

To analyse the specificity of the nucleotide-binding site of FtsA, the affinities for several ATP analogues and other nucleotides were also measured by competition binding assays. As shown in Table 1, the binding affinity was about 10-fold lower when guanosine triphosphate (GTP) or the non-hydrolyzable ATP analogue, ATP- $\gamma$-S, were used in the binding assay. Moreover, the affinity was even lower for adenosine diphosphate (ADP), and the ATP analogue adenosine $5^{\prime}$-( $\beta, \gamma$-imido)triphosphate (AMPPNP). No binding was observed with AMP and with adenosine $5^{\prime}$-( $\beta, \gamma$-methylene)triphosphate (AMP-PCP). The crystal structures of $T$. maritima FtsA (van den Ent and Löwe, 2000) and of other members of the actin superfamily (Hurley, 1996) indicate that the ATP molecule interacts with these proteins mainly by the phosphate groups, located at the bottom of the ATP pocket, while the adenine moiety is exposed to the medium and establishes relatively few interactions with FtsA. Consistent with this, FtsA binds ATP and GTP with a higher affinity than ADP, while no binding was observed for AMP (Table 1). The B. subtilis FtsA has been shown to have an ATPase activity (Feucht et al., 2001), therefore we also analysed the ability of FtsA to hydrolyse ATP. However, as for its E. coli and T. maritima counterparts (van den Ent et al., 2001; J. Mingorance and M. Vicente, unpubl. results), the FtsA protein from $S$. pneumoniae showed no detectable ATPase or GTPase activity under a range of different conditions, including buffer composition, salts, divalent cations, protein concentration, temperature and incubation time (not shown).

\section{FtsA polymerizes in vitro in the presence of ATP and $\mathrm{Mg}^{2+}$}

During the sedimentation velocity analysis in the analytical ultracentrifuge it was observed that after the addition of ATP and $\mathrm{Mg}^{2+}$ a very large structure was formed that sedimented very fast, suggesting the association of FtsA monomers either into aggregates or into high molecularweight polymers (not shown). These complexes where large enough to be pelleted using a tabletop centrifuge, and were formed only in the presence of ATP and $\mathrm{Mg}^{2+}$, while no precipitation was observed in the absence of any of the two (Fig. 3A).

Electron microscopy analysis of the samples in the presence of ATP showed that the complexes formed were long curved polymers (Fig. 4A). Most of the polymeric material was composed of large complex helixes, formed by a pair of paired filaments $(2+2)$ in a corkscrew-like structure (Fig. 4B). Although the structures were quite 

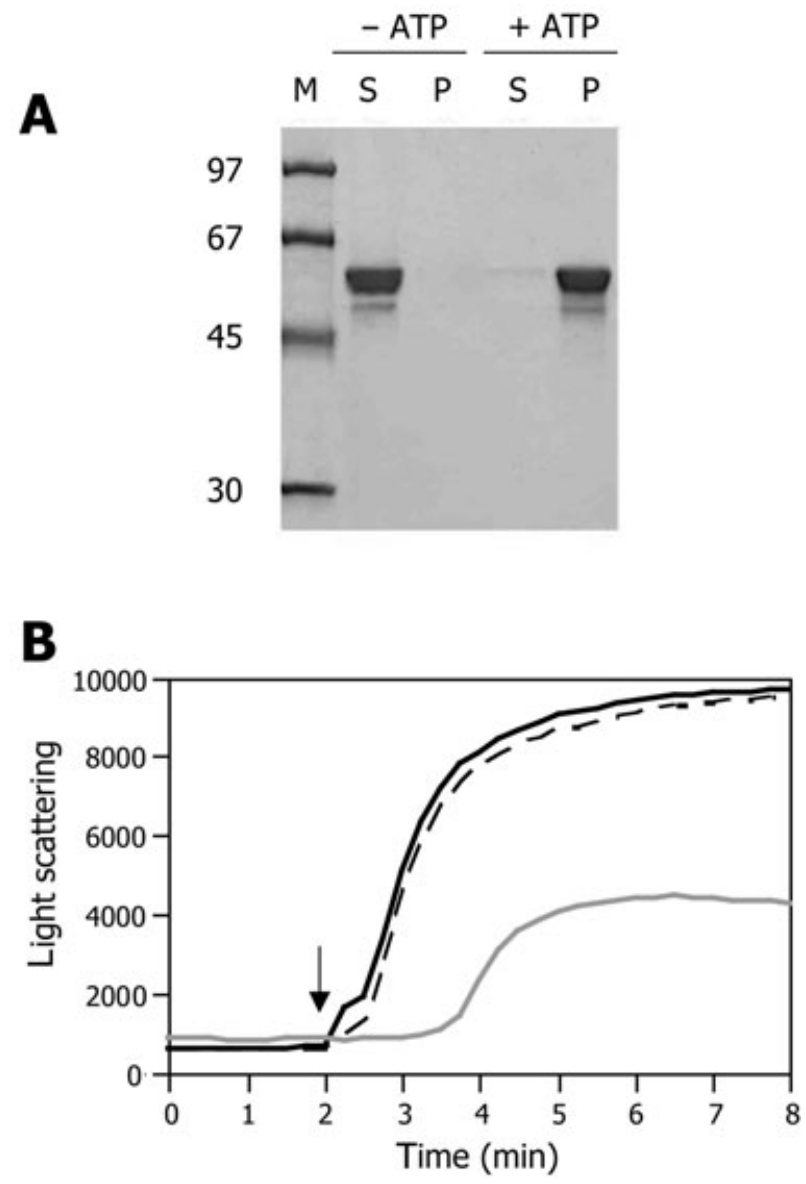

Fig. 3. Nucleotide-dependent polymerization of FtsA.

A. FtsA was incubated in the presence and in the absence of $2 \mathrm{mM}$ ATP for $15 \mathrm{~min}$ at room temperature and centrifuged. Supernatant and pellet were separated and analysed by SDS-PAGE. The figure shows a Coomassie blue stained gel. Lanes: M, Molecular weight markers; S, supernatants; P, pellets; -ATP, no ATP; +ATP, +2 mM ATP. B. Analysis of polymerization by $90^{\circ}$ light scattering. Purified FtsA at a concentration of $0.5 \mathrm{mg} \mathrm{ml}^{-1}$ was equilibrated for several minutes in a fluorimeter cuvette before addition of nucleotide, indicated by the arrow. Black line: 2 mM ATP; dotted line: 0.2 mM ATP; grey line: 2 mM ADP.

regular, they were often bent, and the filaments were often aggregated forming long bundles. Measurements were taken from different areas of the micrographs (Fig. 4B). The average width of the double filament was $8.08 \pm 0.81 \mathrm{~nm}$ and the helical turn was $69.5 \pm 6.6 \mathrm{~nm}$. The T. maritima FtsA monomer has a length of approximately $9 \mathrm{~nm}$ and a diameter of $5 \mathrm{~nm}$ in the central and wider region, although it is narrower at both extremes. This suggests that each single protofilament might be a polymer formed by monomeric subunits interacting in a head-to-tail manner, and that the subunits might be oriented with the longer axis approximately parallel to the axis of the protofilament, similarly to the model proposed by Carettoni et al. (2003) for E. coli FtsA dimerization.
In vitro polymerization of FtsA was studied under several conditions and two factors appeared to be critical: ATP and $\mathrm{MgCl}_{2}$ concentration. Polymerization was observed at all the protein concentrations tested, from $0.075 \mathrm{mg} \mathrm{ml}^{-1}$ up to $1 \mathrm{mg} \mathrm{ml}^{-1}$. ATP concentrations between 0.1 and $5.0 \mathrm{mM}$, and $\mathrm{MgCl}_{2}$ concentrations between 1 and $10 \mathrm{mM}$ promoted polymerization.

As FtsA was able to bind different nucleotides, its polymerization activity in the presence of various nucleotides was also studied. Polymer formation was observed in the presence of either $5 \mathrm{mM}$ ATP or GTP, in agreement with the results of nucleotide binding. FtsA was also able to polymerize in the presence of $5 \mathrm{mM} A D P$ and the nonhydrolyzable ATP analogues, ATP- $\gamma$-S or AMP-PNP. A relatively low level of polymerization was observed with AMP or AMP-PCP, although no binding was detected in competition assays (Table 1 ).

The time-course of the reaction was followed by $90^{\circ}$ light scattering in a fluorimeter (Fig. 3B). With ATP polymerization started after a short lag of about $0.5 \mathrm{~min}$, reached the maximal value after 2-3 min, and remained maximal for at least $1 \mathrm{~h}$. With ADP the curve was also stable for at least $1 \mathrm{~h}$, although there was a lag of $2 \mathrm{~min}$, and the maximal value was about half the one reached with ATP. The shape of the light scattering curves suggested that the polymers might be very stable, or that they might form irreversible aggregates after some time, therefore the same samples were analysed by electron microscopy immediately after the addition of nucleotide or after $24 \mathrm{~h}$ of incubation. The polymers formed with ATP were indeed very stable as they were still found after $24 \mathrm{~h}$, a finding that is consistent with the absence of an ATPase activity. Polymers formed with GTP were indistinguishable from those formed with ATP (not shown). In contrast, ADP-containing polymers were initially very similar to those containing ATP, although they were unstable, appearing as small shapeless aggregates after $24 \mathrm{~h}$ (data not shown). The stability of the ATP-containing polymers was further confirmed by resuspending the precipitate twice in $20 \mathrm{mM}$ Tris- $\mathrm{HCl} \mathrm{pH} 8.0$ without ATP and still recovering most of them in the pellet after incubation followed by centrifugation.

The addition of $5 \mathrm{mM}$ EDTA to the polymerization reaction induced a rapid depolymerization, and the polymers were rapidly reformed after the addition of $5 \mathrm{mM} \mathrm{MgCl}$, showing that, in spite of the high stability of the polymers, polymerization was reversible (not shown).

\section{Discussion}

In this work we report the characterization of the FtsA protein from S. pneumoniae. Although the dcw gene cluster of $S$. pneumoniae is reduced in comparison to those of other bacteria, the gene encoding FtsA maintains a 


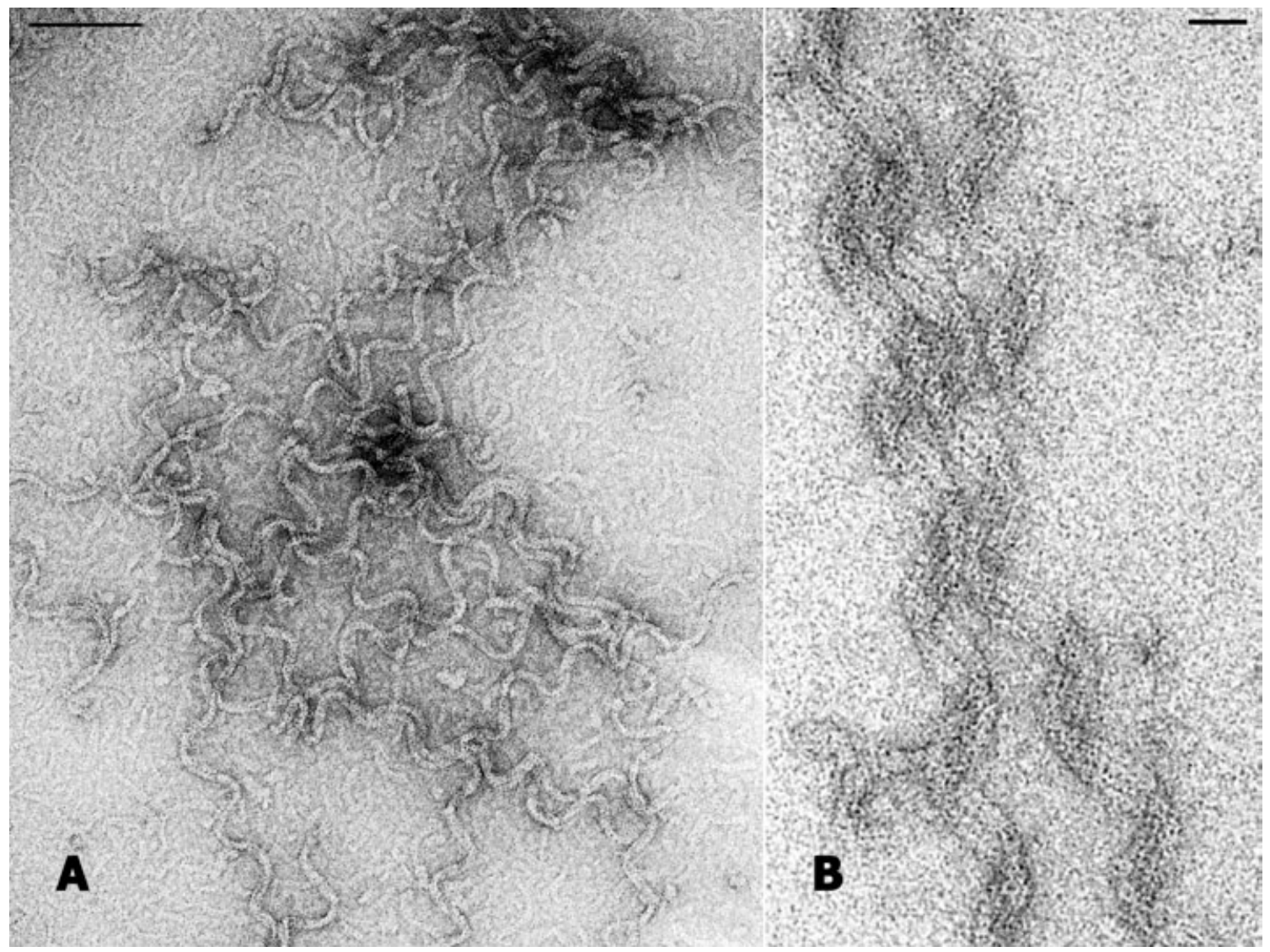

Fig. 4. Electron microscopy of the FtsA polymers.

A. FtsA $\left(0.5 \mathrm{mg} \mathrm{ml}^{-1}\right)$ was incubated with $2 \mathrm{mM} \mathrm{ATP,} \mathrm{applied} \mathrm{to} \mathrm{copper} \mathrm{grids} \mathrm{and} \mathrm{negatively} \mathrm{stained} \mathrm{as} \mathrm{explained} \mathrm{in} \mathrm{the} \mathrm{Experimental} \mathrm{procedures.}$ The scale bar on the upper left side represents $100 \mathrm{~nm}$.

B. Detail of an image taken with minimal dose mode. The scale bar on the upper right side represents $20 \mathrm{~nm}$.

conserved chromosomal position upstream of fts $Z$ (Massidda et al., 1998). As previously reported for E. coli and Caulobacter crescentus (Lutkenhaus and Donachie 1979; Sackett et al., 1998), we found that ftsA is not dispensable in $S$. pneumoniae, as suggested by the inability to recover transformants carrying the inactivated gene. Although polarity effects on the essential $\mathrm{fts} Z$ gene cannot be completely ruled out in these experiments, our method has been shown to reduce this risk in previous experiments in which it allowed the detection of other nonessential S. pneumoniae genes (Fadda et al., 2003) that have been classified as essential by other methods (Thanassi et al., 2002).

The immunostaining of FtsZ and FtsA in dividing cells concurrently at both the closing septa and at the equatorial points, and the polar localization in a small percentage of the cells indicate that both proteins localize in a ringlike structure at an early stage of cell division and remain there throughout the process of septation. The localization of these proteins shows a similar distribution to that for septal markers observed by Morlot et al. (2003), with labelling occurring at the cell centre in dividing cells and at future division sites in daughter cells.

These results are also in agreement with the model proposed for new wall assembly and septation in cocci (Higgins and Shockman, 1970). Experiments, in which the cell wall surface of streptococci was labelled with immunological (Cole and Hahn, 1962), autoradiographic (Briles and Tomasz, 1970) and morphological (Higgins and Shockman, 1970) markers, predicted that in these bacteria new wall assembly is initiated equatorially. In this position, an initial equatorial ring (or wall band) is duplicated and the two resulting rings are progressively separated until they approach the equator of the newborn cells. This event is followed by the cross-wall ingrowth, necessary for division. The previously duplicated equatorial rings became then markers for the future sites of new wall assembly and division of the daughter cells and undergo duplication during the next cell cycle (Higgins and Shockman, 1970; 1976; Tomasz, 2000).

In accordance with the similar localization observed for FtsA and FtsZ in streptococcal cells, yeast two-hybrid 
results showed that both proteins can interact. This interaction has also been demonstrated with the FtsA and FtsZ homologues of several other species, including $E$. coli, $B$. subtilis, C. crescentus, and Staphylocuccus aureus (Descoteaux and Drapeau, 1987; Ma et al., 1997; Wang et al., 1997; Din et al., 1998; Ma and Margolin, 1999; Yan et al., 2000). In addition, yeast two-hybrid experiments also indicate that streptococcal FtsA interacts with itself as does the E. coli counterpart (Yim et al., 2000).

In the absence of added nucleotide, streptococcal FtsA was found to be mostly a monomer, in contrast to $B$. subtilis FtsA that has been found to be present in monomeric and dimeric forms (Feucht et al., 2001). Recently, an FtsA homodimerization model has been proposed that involves a head-to-tail interaction, suggesting that $E$. coli FtsA polymerizes to form actin-like filaments (Carettoni et al., 2003). However, until now no evidence for FtsA polymerization has been reported, although it has been tested under numerous conditions with the protein from the thermophile T. maritima (van den Ent et al., 2001). On the other hand, it has been proposed that both FtsA from E. coli and B. subtilis may form dimers in vivo (Yim et al., 2000; Feucht et al., 2001; Carettoni et al., 2003). Moreover, although no evidence for higher order interactions are available, their existence cannot be ruled out. In fact, E. coli FtsA tends to form disorganized aggregates, precluding in vitro polymerization studies.

Our electron microscopy images show that in the presence of ATP, streptococcal FtsA polymerizes forming long corkscrew structures (Fig. 4). This polymerization is dependent on the presence of nucleotide di- or triphosphates and $\mathrm{Mg}^{2+}$ and represents the first evidence that this protein shares the same ability to polymerize described for other members of the ATP-binding superfamily, including the prokaryotic MreB and ParM proteins (van den Ent et al., 2001; 2002), although both the structure and the dynamics of FtsA filaments are different.

Actin filaments and microtubules are dynamic, and the kinetics of polymerization are modulated by binding and hydrolysis of nucleotide triphosphates (Korn et al., 1987; Carlier, 1994; van den Ent et al., 2002). In contrast, both light scattering experiments and electron microscopy analysis indicate that the FtsA filaments formed in vitro are highly stable, in agreement with the lack of a detectable ATPase activity. The facts that FtsA has a higher affinity for ATP than for ADP, and that the polymers formed with ADP are less stable than those formed with ATP, suggest that the protein might be able to perform an ATP hydrolysis cycle that regulates polymer dynamics, but in vivo this is likely to require the assistance of other proteins.

The affinity of streptococcal FtsA for ATP is low $(\mathrm{IC} 50=8 \mu \mathrm{M})$ compared with other members of the actin superfamily, like DnaK or actin itself (Kapp in the $n M$ range). Nevertheless it is well below the intracellular ATP concentration, that has been estimated to be around 3-5 mM in E. coli (Neuhard and Nygaard, 1987). This, together with the much lower affinity for ADP (IC50 $\approx 1 \mathrm{mM})$, suggests that in vivo most of the protein should be ATP-bound.

We have estimated that a streptococcal cell contains about 2200 molecules of FtsA, which corresponds to a concentration of around $10 \mu \mathrm{M}$. This is about twofold the amount found in B. subtilis (Feucht et al., 2001) and threefold and perhaps as much as 10 times the concentration found in E. coli (Wang and Gayda, 1992; Rueda et al., 2003). The significance of the disproportion on the amount of FtsA in S. pneumoniae with respect to that in $E$. coli or $B$. subtilis has yet to be elucidated, but this protein concentration is high enough to support polymerization in the cell cytoplasm, as it is about five times greater than the lowest concentration that we have tested in vitro. This means that under normal in vivo conditions of high ATP levels, streptococcal FtsA should be a polymer, and suggests that there should be other proteins assisting to control the state of FtsA polymerization during the cell cycle. In addition, we have estimated that a streptococcal cell contains about 3000 copies of FtsZ per cell, corresponding to an FtsA:FtsZ ratio of $1: 1.5$, and thus differing from the 1:5 ratio reported for $B$. subtilis and $E$. coli (Feucht et al., 2001; Rueda et al., 2003). What are the biological reasons for this different ratio, and whether this variation reflects a general difference between cocci and bacilli, are presently unknown. However, the localization of both Penicillin-binding proteins (PBPs) and FtsZ in $S$. pneumoniae cells (Morlot et al., 2003) confirmed previous hypotheses (Lleo et al., 1990; Massidda et al., 1998) that, similarly to rods, cell wall synthesis in coccal S. pneumoniae involves two assembly sites, peripheral and septal, the latter prevailing over the former. It could be speculated then that, differently from rods, where septal synthesis proceeds discontinuously, to maintain the quasi-spherical cell shape in cocci, the septal machinery should be predominant, allowing continuous septal synthesis and constantly requiring large amounts of FtsA. Therefore it is not totally unexpected to find a relatively larger number of FtsA molecules in cocci, especially if FtsA has a crucial role in the assembly of the septal complexes and in their switch to synthesize septal peptidoglycan, as recently proposed (Margolin, 2004).

\section{Experimental procedures}

\section{Bacterial strains and growth conditions}

The S. pneumoniae Rx1 strain, a non-encapsulated wellcharacterized laboratory strain (Ravin, 1959), was used in this study. Rx1 was routinely grown in Tryptone Soya Broth (TSB; Oxoid) or Tryptone Soya Agar (TSA; Oxoid) supplemented with $5 \%$ defibrinated sheep blood and incubated at $37^{\circ} \mathrm{C}$ in an atmosphere of $5 \% \mathrm{CO}_{2}$. When appropriate, 
chloramphenicol was added to the growth medium at a concentration of $4.5 \mu \mathrm{g} \mathrm{ml}^{-1}$.

Escherichia coli $\mathrm{DH} 5 \alpha$ strain was used as a host for cloning and E. coli BL21(DE3) strain and its derivative E. coli BL21(DE3) pLysS strain from Novagen were used as hosts to overexpress the fusion proteins. Luria-Bertani (LB) broth and agar, supplemented with ampicillin $\left(150 \mu \mathrm{g} \mathrm{ml}^{-1}\right)$ and chloramphenicol $\left(34 \mu \mathrm{g} \mathrm{ml}^{-1}\right)$, when required, were used for routine cultures of $E$. coli at $37^{\circ} \mathrm{C}$.

\section{Insertion/deletion mutagenesis}

Streptococcus pneumoniae genomic DNA isolated from strain Rx1 as previously described (Dillard and Yother, 1994) was used as template for PCR experiments. Constructs to inactivate genes by an insertion/deletion mechanism were obtained by a two-step PCR method (Fadda et al., 2003). Three sets of primers, sequences available on request, were used for each construct. PCR-derived fragments were purified using the QIAquick PCR purification kit (Qiagen), mixed in the ratio of $1: 1: 1$ and re-amplified in a second PCR run, using the external primers. Constructs for gene inactivation, obtained as described above, were used to transform $S$. pneumoniae Rx1 competent cells (Fadda et al., 2003). Chromosomal DNA fragments of the corresponding regions not containing the resistance marker were used as a negative control for transformation. Transformants were selected after $24 \mathrm{~h}$ growth on TSA blood agar plates containing chloramphenicol. In all cases where no growth was observed, incubation was continued for $48 \mathrm{~h}$.

\section{Plasmid construction}

For cloning purposes the fts $A$ and $f t s Z$ genes were amplified by PCR from Rx1 S. pneumoniae chromosomal DNA. The upstream and downstream primers, containing the restriction sites for BamHI and EcoRI (underlined), were SpnBFftsA (5'-CGCGGATCCATGGCTAGAGAAGGCTTTTTTACAGG-3') and SpnERftsA (5'-CCGGAATTCCTTGAGCAGCAGCTGTA TCAAATG-3'), and SpnBFftsZ (5'- CGCGGATCCATGACA TTTTCATTTGATACAGCTG-3') and SpnERfts $Z$ (5'-CCG GAATTCCCACTCTCTCGATGAGCACTCA-3') respectively. The amplified fragments were purified, double digested with BamHI/EcoRI (Roche Molecular Biochemicals, Mannheim, Germany), re-purified and ligated to the BamHI-EcoRI digested pRSETA vector (Invitrogen). The ligation mixture was transformed in E. coli $\mathrm{DH} 5 \alpha$ competent cells (Invitrogen) and transformants were selected after overnight growth in LB plates with ampicillin. Clones containing the recombinant plasmids pRSETA_fts $A$ and pRSETA_fts $Z$ were verified by restriction analysis and DNA sequencing of the inserts and used as a source of plasmid DNA to transform E. coli strain BL21(DE3) to produce the corresponding FtsA and FtsZ proteins fused to an His-tag at their $\mathrm{N}$-terminal end (see below).

Similarly, recombinant plasmids to be used in the yeast two-hybrid assays were obtained by cloning the fts $A$ and fts $Z$ genes in the pGBKT7 and pGADT7 vectors (Clontech, Laboratories) respectively. The primer sequences for cloning of the fts genes were the same as those reported above, the only difference being the incorporated restriction sites for cloning, EcoRI (for the forward) and BamHI (for the reverse) in all cases.

\section{Yeast two-hybrid assay}

Protein interactions were tested using the Matchmaker GAL4 Two-Hybrid System 3 (Clontech). The fts $A$ and $\mathrm{fts} Z$ genes were cloned in both yeast two-hybrid vectors, as described above. Yeast strain AH109, was used because it allowed us to screen four reporter genes (ade2, his3, mel1 and lacZ), hence reducing the number of false positives. $\mathrm{AH} 109$ was transformed using the Yeast Transformation Kit (Sigma), accordingly with the manufacturer's instructions. Single transformants were selected in SD medium supplemented with the required amino acids and $10 \mathrm{mg} \mathrm{ml}^{-1} \mathrm{x}-\alpha$-Gal (Clontech). Double transformants were first selected in low stringency medium (leu-, trp-) and then replica-plated in high stringency medium (leu-, trp-, his-, ade-) containing $\mathrm{x}-\alpha$-Gal. Positive and negative internal controls (Clontech) were run in parallel.

\section{Expression and purification of the recombinant proteins}

To overexpress FtsA, plasmid pRSETA_ftsA was transformed in $E$. coli BL21(DE3). A culture (12I) was grown in the medium described by Riesenberg et al. (1991) in a Techfors Bioreactor (Infors, Swiss). FtsA expression was induced with $1 \mathrm{mM}$ IPTG to a final absorbance of $A_{600}=14.3$. The cell pellet (560 g wet weight) was obtained and stored at $-80^{\circ} \mathrm{C}$ until use. The pellet was resuspended in five volumes of

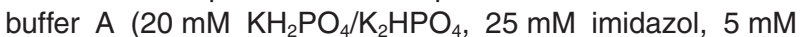
$\mathrm{MgCl}_{2}, 10 \%$ glycerol pH 7.2) containing $0.1 \mathrm{mg} \mathrm{ml}^{-1}$ lysozyme and $800 \mathrm{U}$ benzonase per millilitre, and disrupted using a French Press. The homogenate was kept at $4^{\circ} \mathrm{C}$ for $1.5 \mathrm{~h}$ and then centrifuged for $1 \mathrm{~h}$ at 40000 r.p.m. (rotor $45 \mathrm{Ti}$ ) at $4^{\circ} \mathrm{C}$. As classical $\mathrm{Ni}^{2+}$-chelating chromatography did not allow us to obtain a high purity level, the supernatant was loaded onto a $\mathrm{Zn}^{2+}$-charged HiTrap column (Amersham) equilibrated in buffer $A$. The column was washed with buffer $A$ and elution was performed with buffer A containing $250 \mathrm{mM}$ imidazol. Fractions containing FtsA were pooled and then loaded onto a 2 I Superdex 200 (Amersham) equilibrated in buffer B (Tris$\mathrm{HCl} 20 \mathrm{mM} \mathrm{pH}$ 7.8, NaCl $500 \mathrm{mM}$, glycerol 5\%) at $10 \mathrm{ml} \mathrm{min}^{-1}$. Purified fractions were recovered and concentrated in a Centriprep $30 \mathrm{kDa}$ (Filtron) to obtain a protein concentration of $1-2 \mathrm{mg} \mathrm{ml}^{-1}$. The identity of the protein was confirmed by mass spectrometry. For biochemical experiments, purified FtsA was desalted using a G50 column (Amersham) equilibrated with Tris- $\mathrm{HCl} 20 \mathrm{mM} \mathrm{pH} 7.5,50 \mathrm{mM} \mathrm{NaCl}, 5 \mathrm{mM}$ $\mathrm{MgCl}_{2}$.

A similar two-step chromatography procedure was used for FtsZ purification, except that it was performed in a $\mathrm{Ni}^{2+}$ charged column on a small scale. E. coli BL21(DE3) pLysS cells were used to express the protein from plasmid pRSETA_fts $Z$. The pellet (16 g wet weight), obtained from a 4 I culture induced with $1 \mathrm{mM}$ IPTG to a final absorbance of $A_{600}=2$, was disrupted as described above. Purification was achieved in a $\mathrm{Ni}^{2+}$-charged column, using the His-Bind Kit (Novagen), following the manufacturer's instructions. The eluate was loaded onto a $120 \mathrm{ml}$ Superdex 200 column (Amersham) equilibrated in buffer $B$. The integrity and purity of the 
His-tagged fusion FtsZ was verified by SDS-PAGE gel and quantified using the Bradford method (Bio-Rad).

\section{Production of anti-FtsA and anti-FtsZ antibodies}

Polyclonal antibodies anti-FtsZ and anti-FtsA were obtained from New Zealand rabbits inoculated with purified FtsZ and FtsA recombinant proteins respectively, as described by Harlow and Lane (1988). The FtsZ protein was separated by SDS-PAGE and the corresponding band was cut from the gel, fragmented and used for immunization. The purified FtsA protein suspended in PBS $1 \times$, containing $0.1 \% \beta$-mercaptoethanol and $0.5 \%$ SDS to increase immunogenicity, was used to inoculate the rabbits. No cross-reaction in any of the preimmune sera was observed with any $S$. pneumoniae or $E$. coli protein.

\section{Cellular immunolocalization of the Fts proteins}

To localize FtsA and FtsZ proteins, S. pneumoniae Rx1 cells were cultured in TSB medium and monitored turbidimetrically at $650 \mathrm{~nm}$ until they reached an OD of 0.6. Cultures $(4 \mathrm{ml})$ were rapidly chilled in an ice bath, centrifuged $(10000 \mathrm{~g}$, $\left.15 \mathrm{~min}, 4^{\circ} \mathrm{C}\right)$, washed in $10 \mathrm{mM}$ phosphate $(\mathrm{pH} \mathrm{7.0)}$ and fixed in $1 \mathrm{ml}$ of paraformaldehyde $2 \%$ and glutaraldehyde $0.05 \%$ in PBS $1 \times$ for $4 \mathrm{~h}$ at $4^{\circ} \mathrm{C}$. Fixed cells were washed with PBS and stored at $4^{\circ} \mathrm{C}$ until use. Small pellets of fixed cells were cryoprotected with glycerol, applied to small pieces of filter paper, and quick-frozen in liquid ethane. Frozen specimens were transferred to a Reichert-Jung AFS freeze-substitution unit (Leica, Vienna, Austria) for $48 \mathrm{~h}$ at $-90^{\circ} \mathrm{C}$ in a mixture of methanol and $0.5 \%(\mathrm{w} / \mathrm{v})$ uranyl acetate for complete substitution of the water of the sample. After freeze-substitution, samples were infiltrated in Lowicryl K4M (EML Laboratories, Berkshire, UK) at $30^{\circ} \mathrm{C}$ and polymerized with UV light.

Ultrathin sections of the samples were collected on 200mesh gold grids covered with Formvar and carbon and processed for immunogold labelling as follows: after $40 \mathrm{~min}$ blocking with Tris buffer-gelatin (TBG, $30 \mathrm{mM}$ Tris- $\mathrm{Hcl}$, pH 8.0, $150 \mathrm{mM} \mathrm{NaCl}, 0.1 \%$ bovine serum albumin and $1 \%$ gelatin), sections were incubated for $1 \mathrm{~h}$ in TBG containing anti-FtsA (1:100) or anti-FtsZ (1:450) and then washed with PBS. Next, grids were floated on three drops of TBG and incubated $10 \mathrm{~min}$ on the last drop before a $45 \mathrm{~min}$ incubation with $10 \mathrm{nM}$ gold-labelled goat anti-rabbit IgG (1:40) in TBG. Grids were then washed in PBS and distilled water before staining with saturated uranyl acetate for $30 \mathrm{~min}$, followed by lead citrate for $1 \mathrm{~min}$. Images were collected in JEOL 1200-EXII electron microscope (Zeiss) operating at $100 \mathrm{kV}$. Electron micrographs were scanned using an Epson Stylus PHOTO 890 scanner and Picture Publisher 8 software.

For immunofluorescence, exponentially growing cells were fixed and treated as described by Morlot et al. (2003). Cells were then transferred onto SuperFrost Plus slides (MenzelGlaser). The slides were washed twice with PBS, air-dried, dipped in methanol at $-20^{\circ} \mathrm{C}$ for $10 \mathrm{~min}$ and allowed to dry. After rehydratation with PBS, the slides were blocked for $1 \mathrm{~h}$ at room temperature with $2 \%(\mathrm{w} / \mathrm{v})$ bovine serum albumin, $0.2 \%$ Triton X-100 (v/v) in PBS (BSA-PBST), and for $1 \mathrm{~h}$ with appropriate dilutions of anti-FtsA and anti-FtsZ antibodies in
BSA-PBST. The slides were then washed five times with PBS and incubated for $30 \mathrm{~min}$ with a 1:150 dilution of fluorescein anti-rabbit IgG (Vector Laboratories) in BSA-PBST. To check the specificity of the secondary antibody, in negative controls incubation with primary antibodies was omitted. Slides were observed using a ZEISS Axioplan 2, equipped with a 100x Achroplan phase-contrast and fluorescence objective and standard filter sets. Photographs were taken with an Axiophot 2 camera, scanned and processed with Adobe Photoshop 6.0.

\section{ATP binding and ATP hydrolyis}

Binding affinities of different nucleotides and ATP analogues were determined by competition with the binding of $\left[\gamma^{-{ }^{33}} \mathrm{P}\right]$ ATP using a nitrocellulose filter-binding assay (Mingorance et al., 2001). Increasing concentrations of unlabelled nucleotides or ATP analogues, from 0 to $5 \mathrm{mM}$, were incubated in $20 \mu$ of buffer (25 mM Tris pH 7.5, $2.5 \mathrm{mM} \mathrm{MgCl}_{2}, 100 \mathrm{mM}$ $\mathrm{KCl}$ ) in the presence of $0.2 \mathrm{mg} \mathrm{ml}^{-1} \mathrm{FtsA}$ and at constant $\left[\gamma^{-33} \mathrm{P}\right]$-ATP concentration $(33 \mathrm{nM})$. Samples were done in duplicate, and competition was allowed for $30 \mathrm{~min}$ at room temperature. The reaction mixture $(15 \mu \mathrm{l})$ was applied on a $0.45 \mu \mathrm{m}$ nitrocellulose membrane and filtered using a 96well-Bio-Dot apparatus (Bio-Rad). Membranes were washed three times with $100 \mu \mathrm{l}$ of ice-cold wash buffer [25 mM Tris $\mathrm{pH} 8,50 \mathrm{mM} \mathrm{NaCl}, 5 \mathrm{mM} \mathrm{MgSO}_{4}, 0.005 \%$ Triton X-100, $\left.20 \mathrm{mM}\left(\mathrm{NH}_{4}\right)_{2} \mathrm{SO}_{4}\right]$, and then dried. Quantification of bound $\left[\gamma^{-33} \mathrm{P}\right]$-ATP was determined using a Storm fluorescence reader (Amersham Biosciences) and a $\beta$-counter. Calculation of the affinities (IC50) was done using the GraFit 5 program (Erithacus Software), and the following equation: $y=$ Range/ $\left[1+(x / I C 50)^{s}\right]$, where $x$ is the log of the competing nucleotide concentration, $y$ is the radioactivity retained in the filters (c.p.m.), range is the maximum $y$ range, and $s$ is a slope factor. The equation assumes that $y$ falls with increasing $x$.

Experiments to detect ATP hydrolysis were done using $[\gamma$ $\left.{ }^{32} \mathrm{P}\right]$-ATP and thin layer chromatography as described in Mingorance et al. (2001) for the hydrolysis of GTP by FtsZ.

\section{Polymerization assays and detection of FtsA polymers}

For standard polymerization assays, purified FtsA $\left(0.4 \mathrm{mg} \mathrm{ml}^{-1}\right)$ was incubated for $15 \mathrm{~min}$ at $24^{\circ} \mathrm{C}$ in $50-100 \mu \mathrm{l}$ of polymerization buffer $(20 \mathrm{mM}$ Tris $\mathrm{pH} 8.0,50 \mathrm{mM} \mathrm{NaCl}$, $5 \mathrm{mM} \mathrm{MgCl}_{2}$ ) in the presence or the absence of $2 \mathrm{mM} \mathrm{ATP.}$ The reaction mixture was centrifuged at $20000 \mathrm{~g}$ for $15 \mathrm{~min}$ at $4^{\circ} \mathrm{C}$ in a microfuge. The supernatant and the resuspended pellet were analysed by SDS-PAGE eletrophoresis on a $12.5 \%$ Criterion Precast Gels (Bio-Rad) and visualized after staining of the gels with Bio-Safe Coomassie G250 stain (BioRad). Alternatively, different protein concentrations were assayed with a range of ATP $(0-5 \mathrm{mM})$ and $\mathrm{MgCl}_{2}(0-10 \mathrm{mM})$ concentrations.

Polymerization with different nucleotide triphosphates (5 mM) was assayed as described above. All the experiments included a positive control with ATP and a negative control with no nucleotides.

For sedimentation velocity assays, purified and desalted FtsA protein was centrifuged in a Beckman XLA analytical 
ultracentrifuge at a concentration of $0.4 \mathrm{mg} \mathrm{ml}^{-1}$. Differential sedimentation coefficient distributions, c(s), were calculated by least-squares boundary modelling of sedimentation velocity data using the program SEDFIT (Schuck, 2000; Schuck et al., 2002).

Light scattering was measured in a Hitachi F-2500 fluorescence spectrophotometer. Excitation and emission wavelengths were set to $350 \mathrm{~nm}$ with slid widths of $5 \mathrm{~nm}$. All the experiments were done at $25^{\circ} \mathrm{C}$ as described in Mingorance et al. (2001).

FtsA polymers were observed by electron microscopy. FtsA was incubated in $100 \mu \mathrm{l}$ of polymerization buffer, as described above. ATP or ADP were added to $2 \mathrm{mM}$ final concentration and polymer formation was checked at different times. Samples were applied to a 400-mesh collodioncoated glow-discharged copper grid, negatively stained with $2 \%$ uranyl acetate, and inspected with a JEOL 1200-EXII electron microscope. To calculate the average width of the paired filament and the helical turn of the polymers, 25 regular structures were chosen and measured with the Object Image version 1.62 software (N. Vischer, University of Amsterdam).

\section{Protein quantification by Western blotting}

The total amount of FtsA and FtsZ proteins in streptococcal cells was determined by Western blotting. S. pneumoniae cells were cultured in TSB and monitored turbidimetrically at $650 \mathrm{~nm}$ until they reached an OD of 0.45 . Cultures $(100 \mathrm{ml})$ were rapidly chilled in an ice bath, centrifuged in a Sorvall centrifuge $\left(20000 \mathrm{~g}, 15 \mathrm{~min}, 4^{\circ} \mathrm{C}\right)$, washed once in $10 \mathrm{mM}$ phosphate $(\mathrm{pH} 7.0)$ and resuspended in $1 \mathrm{ml}$ of the same buffer. Cells were disrupted mechanically using glass beads in a Hybaid Ribolyser (Hybaid, Ashford, UK), according to the manufacturer's instructions. After breaking, cells were mixed 1:1 with Laemmli buffer (Bio-Rad) and boiled for $5 \mathrm{~min}$. Crude extracts were stored at $-20^{\circ} \mathrm{C}$ until use. Different amounts of FtsA and FtsZ purified proteins were prepared and treated 1:1 with Laemmli buffer as above. Proteins were separated on $12.5 \%$ Criterion Precast Gels (Bio-Rad) and transferred to a nitrocellulose membrane (Protran BA83, Schleicher and Schuell) at $100 \mathrm{~V}$ for $30 \mathrm{~min}$ with a Criterion Blotter apparatus (Bio-Rad). After transfer, membranes were stained with Ponceau S (Sigma-Aldrich) and then incubated in 5\% non-fat dry milk in PBST (PBS, $0.05 \%$ Tween) $\mathrm{O} / \mathrm{N}$ at $4^{\circ} \mathrm{C}$. After blocking, membranes were incubated with anti-FtsA (1:30 000) or antiFtsZ $(1: 10$ 000) antibody solution in PBST for $1 \mathrm{~h}$ at room temperature and, after washing, with HRP-conjugated antibodies (Bio-Rad). Finally, chemiluminescent bands were detected using the Immun-Star HRP Chemiluminescent Kit (Bio-Rad) and Kodak Biomax light films. Cell number was determined by viable counts on TSA blood agar plates in duplicate. Quantitative analysis was performed with the Quantity One program (Bio-Rad).

\section{Acknowledgements}

This work has been financed by the EC project QLK3-CT2000-00079 (SANITAS) within the Fifth Framework Program. Work in M.V. laboratory was also supported by grants
$\mathrm{BIO} 2000-0451-\mathrm{P} 4-02$ and $\mathrm{BIO} 2001-1542$ from the Ministerio de Ciencia y Tecnología. Work in O.M. laboratory was also supported by ex-60\% funds from MURST. We thank Dr Carlos Alfonso, Centro de Investigaciones Biológicas (CSIC), for his assistance with analytical centrifugation; Rocío Arranz and Cristina Patiño, Centro Nacional de Biotecnología (CSIC), for the electron microscopy; Maria Grazia Ennas, Dipartimento di Citomorfologia (Università di Cagliari) for her help with immunofluorescence; Daniela Fadda (Università di Cagliari), Monique Fairley (Aventis Pharma) and Marta García-Ovalle (CSIC) for their valuable help.

\section{References}

Addinall, S.G., and Lutkenhaus, J. (1996) FtsA is localized to the septum in an FtsZ dependent manner. J Bacteriol 178: 7167-7172.

Ayala, J.A., Garrido, T., de Pedro, M.A., and Vicente, M. (1994) Molecular biology of bacterial septation. In Bacterial Cell Wall. Ghuysen, J.M., and Hakenbeck, R. (eds). Amsterdam: Elsevier Science Publishers, pp. 73-101.

Baltz, R.H., Norris, F.H., Matsushima, P., DeHoff, B.S., Rockey, P., Porter, G., et al. (1998) DNA sequence sampling of the Streptococcus pneumoniae genome to identify novel targets for antibiotic development. Microb Drug Resist 4: 1-9.

Beall, B., and Lutkenhaus, J. (1992) Impaired cell division and sporulation of a Bacillus subtilis strain with the ftsA gene deleted. J Bacteriol 174: 2398-2403.

Bork, P., Sander, C., and Valencia, A. (1992) An ATPase domain common to prokaryotic cell cycle proteins, sugar kinases, actin, and hsp70 heat shock proteins. Proc Natl Acad Sci USA 89: 7290-7294.

Briles, E.B., and Tomasz, A. (1970) Radioautographic evidence for equatorial wall growth in a gram-positive bacterium. Segregation of choline-- ${ }^{3} \mathrm{H}$-labeled teichoic acid. $J$ Cell Biol 47: 786-790.

Carettoni, D., Gómez-Puertas, P., Yim, L., Mingorance, J., Massidda, O., Vicente, M., et al. (2003) Phage-display and correlated mutations identify an essential region of subdomain $1 \mathrm{C}$ involved in homodimerization of Escherichia coli FtsA. Proteins 50: 192-206.

Carlier, M.F. (1994) Actin polymerization: regulation by divalent metal ion and nucleotide binding, ATP hydrolysis and binding of myosin. In Actin: Biophysics, Biochemistry, and Cell Biology. Estes J.E., and Higgins P.J. (eds). New York: Plenum Press, pp. 71-81.

Claverys, J.P., Dintilhac, A., Pestova, E.V., Martin, B., and Morrison, D.A. (1995) Construction and evaluation of new drug-resistance cassettes for gene disruption mutagenesis in Streptococcus pneumoniae, using an ami test platform. Gene 164: 123-128.

Cole, R.M., and Hahn, J.J. (1962) Cell wall replication in Streptococcus pyogenes. Science 135: 722-724.

Dai, K., and Lutkenhaus, J. (1992) The proper ratio of FtsZ to FtsA is required for cell division to occur in Escherichia coli. J Bacteriol 174: 6145-6151.

Descoteaux, A., and Drapeau, G.R. (1987) Regulation of cell division in Escherichia coli $\mathrm{K}-12$ : probable interactions among proteins FtsQ, FtsA, and FtsZ. J Bacteriol 169: 1938-1942. 
Dewar, S.J., Begg, K.J., and Donachie, W.D. (1992) Inhibition of cell division initiation by an imbalance in the ratio of FtsA to FtsZ. J Bacteriol 174: 6314-6316.

Dillard, J.P., and Yother, J. (1994) Genetic and molecular characterization of capsular polysaccharide biosynthesis in Streptococcus pneumoniae type 3. Mol Microbiol 12: 959972.

Din, N., Quardokus. E.M., Sackett, M.J., and Brun, Y.V. (1998) Dominant C-terminal deletions of FtsZ that affect its ability to localize in Caulobacter and its interaction with FtsA. Mol Microbiol 27: 1051-1063.

van den Ent, F., and Löwe, J. (2000) Crystal structure of the cell division protein FtsA from Thermotoga maritima. EMBO J 19: 5300-5307.

van den Ent, F., Amos, L.A., and Löwe, J. (2001) Prokaryotic origin of the actin cytoskeleton. Nature 413: 39-44.

van den Ent, F., Møller-Jensen, J., Amos, L.A., Gerdes, K., and Löwe, J. (2002) F-actin-like filaments formed by plasmid segregation protein ParM. EMBO J 21: 6935-6943.

Errington, J., Daniel, R.A., and Scheffers, D.-J. (2003) Cytokinesis in bacteria. Microbiol Mol Biol Rev 67: 52-65.

Fadda, D., Pischedda, C., Caldara, F., Whalen, M.B., Anderluzzi, D., Domenici, E., and Massidda, O. (2003) Characterization of $\operatorname{div} I V A$ and other genes located in the chromosomal region downstream of the dcw cluster in Streptococcus pneumoniae. J Bacteriol 185: 6209-6014.

Feucht, A., Lucet, I., Yudkin, M.D., and Errington, J. (2001) Cytological and biochemical characterization of the FtsA cell division protein of Bacillus subtilis. Mol Microbiol 40: 115-125.

Harlow, E., and Lane, D. (1988) Antibodies. Cold Spring Harbor, New York: Cold Spring Harbor Laboratory Press, pp. 53-137.

Higgins, M.L., and Shockman, G.D. (1970) Model for cell wall growth of Streptococcus faecalis. J Bacteriol 101: 643648.

Higgins, M.L., and Shockman, G.D. (1976) Study of a cycle of cell wall assembly in Streptococcus faecalis by threedimensional reconstructions of thin sections of cells. J Bacteriol 127: 1346-1358.

Huang, J., Cao, C., and Lutkenhaus, J. (1996) Interaction between FtsZ and inhibitors of cell division. $J$ Bacteriol 178: $5080-5085$.

Hurley, J.H. (1996) The sugar kinase/heat shock protein 70/ actin superfamily: implications of conserved structure for mechanism. Annu Rev Biophys Biomol Struct 25: 137162.

Korn, E.D., Carlier, M.F., and Pantaloni, D. (1987) Actin polymerization and ATP hydrolysis. Science 238: 638-644.

Lleo, M.M., Canepari, P., and Satta, G. (1990) Bacterial cell shape regulation: testing of additional predictions unique to the two-competing-sites model for peptidoglycan assembly and isolation of conditional rod-shaped mutants from some wild-type cocci. J Bacteriol 172: 3758-3771.

Lutkenhaus, J., and Donachie, W. (1979) Identification of the ftsA gene product. J Bacteriol 137: 1088-1094.

Ma, X., and Margolin, W. (1999) Genetic and functional analyses of the conserved C-terminal core domain of Escherichia coli FtsZ. J Bacteriol 181: 7531-7544.

Ma, X., Ehrhardt, D.W., and Margolin, W. (1996) Colocalization of cell division proteins FtsZ and FtsA to cytoskeletal structures in living Escherichia coli cells by using green fluorescent protein. Proc Natl Acad Sci USA 93: 1299813003.

Ma, X., Sun, Q., Wang, R., Singh, G., Jonietz, E.L., and Margolin, W. (1997) Interactions between heterologous FtsA and FtsZ proteins at the Z-ring. $J$ Bacteriol 179: 6788-6797.

Margolin, W. (2000) Themes and variations in prokaryotic cell division. FEMS Microbiol Rev 24: 531-548.

Margolin, W. (2004) The assembly of proteins at the cell division site. In Molecules in Time and Space: Bacterial Shape, Division and Phylogeny. Vicente, M., Tamames, J., Valencia, A., and Mingorance, J. (eds). New York: Kluwer Academic/Plenum Publishers, pp. 79-102.

Massidda, O., Anderluzzi, D., Friedli, L., and Feger, G. (1998) Unconventional organization of the division and cell wall gene cluster of Streptococcus pneumoniae. Microbiology 144: 3069-3078.

Mingorance, J., Rueda, S., Gómez-Puertas, P., Valencia, A., and Vicente, M. (2001) Escherichia coli FtsZ polymers contain mostly GTP and have a high nucleotide turnover. Mol Microbiol 41: 83-91.

Morlot, C., Zapun, A., Dideberg, O., and Vernet, T. (2003) Growth and division of Streptococcus pneumoniae: localization of the high molecular weight penicillin-binding proteins during the cell cycle. Mol Microbiol 50: 845-855.

Neuhard, J., and Nygaard, P. (1987) Escherichia Coli and Salmonella Typhimurium: Cellular and Molecular Biology, vol. 1. Neidhardt, F.C., Ingraham, J.L., Low, K.B., Magasanik, B., Schaechter, M., and Umbarger, H.E. (eds). Washington, DC: American Society for Microbiology Press, pp. 445-473.

Nikolaichik, Y.A., and Donachie, W.D. (2000) Conservation of gene order amongst cell wall and cell division genes in Eubacteria, and ribosomal genes in Eubacteria and Eukaryotic organelles. Genetica 108: 1-7.

Pucci, M.J., Thanassi, J.A., Discotto, L.F., Kessler, R.E., and and. Dougherty, T.J. (1997) Identification and characterization of cell wall cell division gene clusters in pathogenic gram-positive cocci. J Bacteriol 179: 5632-5635.

Ravin, A.W. (1959) Reciprocal capsular transformations of pneumococci. J Bacteriol 77: 296-309.

Riesenberg, D., Schulz, V., Knorre, W.A., Pohl, H.D., Korz, D., Sanders, E.A., et al. (1991) High cell density cultivation of Escherichia coli at controlled specific growth rate. $J$ Biotechnol 20: 17-28.

Rueda, S., Vicente, M., and Mingorance, J. (2003) Concentration and assembly of the division ring proteins FtsZ, FtsA, and ZipA during the Escherichia coli cell cycle. $J$ Bacteriol 185: 3344-3351.

Sackett, M.J., Kelly, A.J., and Brun, Y.V. (1998) Ordered expression of fts $Q A$ and fts $Z$ during the Caulobacter crescentus cell cycle. Mol Microbiol 28: 421-434.

Sánchez, M., Valencia, A., Ferrándiz, M.J., Sander, C., and Vicente, M. (1994) Correlation between the structure and biochemical activities of FtsA, an essential cell division protein of the actin family. EMBO J 13: 4919-4925.

Schuck, P. (2000) Size distribution analysis of macromolecules by sedimentation velocity ultracentrifugation and Lamm equation modeling. Biophys J 78: 1606-1619.

Schuck, P., Perugini, M.A., Gonzales, N.R., Howlett, G.J., 
and Schubert, D. (2002) Size-distribution analysis of proteins by analytical ultracentrifugation: Strategies and application to model systems. Biophys J 82: 1096-1111.

Tamames, J., González-Moreno, M., Mingorance, J., Valencia, A., and Vicente, M. (2001) Bringing gene order into bacterial shape. Trends Genet 17: 124-126.

Thanassi, J.A., Hartman-Newman, S.L., Dougherty, T.J., Dougherty, B.A., and Pucci, M.J. (2002) Identification of 113 conserved essential genes using a high-throughput gene disruption system in Streptococcus pneumoniae. Nucleic Acids Res 30: 3152-3162.

Tomasz, A. (2000) Streptococcus pneumoniae: functional anatomy. In Streptococcus Pneumoniae: Molecular Biology and Mechanisms of Disease. Tomasz, A. (ed.). New York: Mary Ann Liebert, pp. 9-21.

Vicente, M., and Errington, J. (1996) Structure, function and controls in microbial division. Mol Microbiol 20: 1-7.
Wang, H., and Gayda, R.C. (1992) Quantitative determination of FtsA at different growth rates in Escherichia coli using monoclonal antibodies. Mol Microbiol 6: 25172524.

Wang, X., Huang, J., Mukherjee, A., Cao, C., and Lutkenhaus, J. (1997) Analysis of the interaction of FtsZ with itself, GTP, and FtsA. J Bacteriol 179: 55515559.

Yan, K., Pearce, K.H., and Payne, D.J. (2000) A conserved residue at the extreme $\mathrm{C}$-terminus of $\mathrm{FtsZ}$ is critical for the FtsA-FtsZ interaction in Staphylocuccus aureus. Biochem Biophys Res Commun 270: 387-392.

Yim, L., Vandenbussche, G., Mingorance, J., Rueda, S., Casanova, M., Ruysschaert, J.M., and Vicente, M. (2000) Role of the carboxy terminus of Escherichia coli FtsA in self interaction and cell division. $J$ Bacteriol 182: 63666373. 